\title{
One-Dimensional Warranty Policies Analysis for Remanufactured Products in Reverse Supply Chain
}

\author{
Ammar Y. Alqahtani ${ }^{1}$, Surendra M. Gupta ${ }^{2}$, and Kenichi Nakashima ${ }^{3}$ \\ ${ }^{1}$ King Abdulaziz University, Department of Industrial Engineering, Jeddah 22254, Saudi Arabia; 2Northeastern University \\ ${ }^{2}$ Laboratory for Responsible Manufacturing, Department Mechanical and Industrial Engineering, Boston, MA, 02115 U.S.A \\ ${ }^{3}$ Kanagawa University, Department of Industrial Engineering and Management, Yokohama, 221-8686, Japan
}

\begin{abstract}
This paper presents a non-renewable basic one-dimensional combination warranty policy analysis for an Advanced Remanufacturing-To-Order system for Sensor-embedded products (SEPs). The goal of the proposed approach is to determine how to predict a non-renewing one-dimensional Free Replacement and ProRata combination warranty period for the disassembled components and remanufactured products using the sensor information about the age of every end-of-life (EOL) retrieve products on hand to meet remanufactured product and component demands while minimizing the cost associated with warranty and maximizing manufacturer's profit. Different simulation scenarios are explained and a case example is presented for illustration of the model applicability.
\end{abstract}

Key Words : Warranty Analysis, End-of-life, Remanufacturing, Sensor embedded products, Simulation, Onedimensional, Combination warranty.

\section{Introduction}

The accelerated rate of technology development and customers' desire for newer models are resulting in shorter product life cycles and an increase in rates of product disposal. As a result, landfill sites and natural resources are reaching a critical state, forcing governments to mandate tighter environmental regulations on manufacturers. When products are deemed no longer useful, firms reclaim them to fulfil the requirements of these new regulations, raising customers' awareness of environmental issues in the process. Special facilities created for product recovery minimize the amount of waste sent to landfills, as materials, parts and components from the end-of-life (EOL) products pass through stages of retrieval, recycling, refurbishment, and remanufacturing. Additionally, the economic benefits from such facilities make product recovery an increasingly attractive option [14].

The chief concern in such product recovery processes is the uncertainty in quantity and quality of recoverable materials, due primarily to the lack of any information about the condition of components before disassembly. The obvious solution is to test every component after disassembling them. This, however, can harm the profitability of a remanufacturer depending on testing time and testing costs. Furthermore, if the test shows the component is non-functional, then all the allocated time and resources \footnotetext{
ARABIA

aaylqahtani@kau.edu.sa

(Received January 20, 2017)

(Revised March 12, 2017)

(Accepted April 18, 2017)
}

Corresponding Author: Ammar Y. Alqahtani

King Abdulaziz University, Department of Industrial Engineering, Faculty of Engineering, Jeddah, 22254 SAUDI are wasted.

The quality of a remanufactured product is a concern for consumers. Therefore, the consumers are unsure if the remanufactured products will satisfy performance expectations. This ambiguity about a remanufactured product could lead the consumer to decide against buying it. With such apprehension held by consumers, remanufacturers often seek market mechanisms that provide assurance about the durability of the products. One strategy that remanufacturers often use is to offer warranties on their products. Warranty, by definition, is a contractual obligation incurred by a manufacturer (vendor/seller) in connection with the sale of a product. The purpose of warranty is to establish liability in the event of a premature failure of an item or the inability of the item to perform its intended function. The contract specifies the promised product performance and when it is not met, the redress available to the buyer as compensation. Product warranties have several major functions: First, as insurance and protection, permitting buyers to transfer the risk of product failure to sellers. Second, product warranties can also signal product reliability to customers. Finally, the sellers use warranties to extract additional profitability. There are a few articles and books that consider warranty policies for new products' supply chain management. None, however, consider warranty for the remanufactured products' reverse and closed-loop supply chain management.

The next section presents a literature review in relevant areas. Advanced Remanufacturing-To-Order system used in the study is stated in Section 3. Section 4 describes the Design-Of-Experiments study process. One-Dimensional Product Warranty is presented in Section 5. Notation and Formulation used in this study are discussed in Section 
6. Section 7 presents numerical example Finally, Section 8 and Section 9 present the results and some concluding remarks.

\section{Literature Review}

This section provides a literature review on the issues considered in this research. First, a brief review on environmentally conscious manufacturing and product recovery are presented. Then, discussion on smart sensorembedded products studies is offered. Finally, brief discussion on product warranty.

\subsection{Environmentally Conscious Manufacturing and Product Recovery}

The number of studies dealing with the end-of-life (EOL) phase of a product has attracted a lot of attention from researchers [11],[17]. This is due to environmental factors, government regulations and public demands, and then again, to potential economical profits that could be obtained by implementing reverse logistics and product recycling resolutions. Manufacturers try to deal with consumer awareness towards environmental concerns and stricter environmental regulations by building up facilities which involve the minimization of the amount of waste sent to landfills by recovering materials and components from returned or EOL products [12].

During product recovery, the disassembly process plays an important role since it allows for selective separation of desired parts and materials. EOL products consisting of missing and/or nonfunctional components raise the uncertainty factor associated with the disassembly yield. Sensor-embedded products (SEPs) eliminate most uncertainties involved with EOL management by providing life-cycle information [13],[29]. This includes information about the contents of each product and component conditions that enables the estimation of remaining useful life of the components. Once the data about the product is captured, it is possible to make optimal EOL decisions without any preliminary disassembly or inspection operations [?],[16]. After the components are retrieved, the products can be remanufactured.

\subsection{Smart Sensor Embedded Products}

The expansion of technology has allowed manufacturer to build smart sensors in smaller sizes and lower cost. The acquisition of the essential life-cycle components of a product with smart sensor embedded is presented by Zeid et al.[31], Vadde et al.[30]. Other research aims to explore if the use of embedded sensors will improve the efficiency of product life-cycle management. A comprehensive survey on the commercial sensor systems used in health management for electronic products and systems done by Pecht [27]. Fang et al.[7] conducted another comprehensive survey about reviewed the current practices toward the development of embedded smart sensors in products in two primary aspects, namely, embedding smart sensors in products and representing and interpreting sensor data.

To provide easy access for retrieving, updating, and managing of information in the product life-cycle radiofrequency identification (RFID) tags have been Kiritsis et al.[21], Parlikad and McFarlane [26]. The practical and economic impact of using RFID in alleviating the quality uncertainty associated with the remanufacturing processes has been investigated by Kulkarni et al.[22]. Ferrer et al.[8] stated an application of RFIDs where active RFID can be used for easy identification and localization of components within a remanufacturing facility and passive RFID can be permanently tagged onto components of remanufacturable products at the beginning of their service life. The retrieved information from embedded smart sensors product has been studied in product EOL recovery processes decision making.

\subsection{Product Warranty}

The quality and reliability of a remanufactured product is a concern for the buyers. That is, the buyers are unsure if the remanufactured products will provide the anticipated performance. This opacity about a remanufactured product could point the consumer against buying it. With such apprehension held by buyers, remanufacturers often seek market mechanisms that provide assurance about the reliability of the products. One tactic that the remanufacturers often use is to offer warranties on their products [5],[6],[25]. Product warranties have different major functions. First is insurance and protection, permitting buyers to transfer the risk of product failure to sellers [15]. Then, product warranties can also signal product reliability to customers [4],[9],[28]. Finally, the sellers use warranties to extract additional profitability [24]. There are a few articles and books that consider warranty policies for new products' supply chain management. There are only a handful of papers that consider the warranty for remanufactured products' reverse and closed-loop supply chain management [?]. Modeling and analyzing the warranty cost for used product is a new research field with a limited number of publications. The warranty policy and its effect on consumer behavior has been studied by Liao et al.[23]. The study proposed a mathematical-statistical model where decisions involve pricing of returned used products (cores), the degree of their remanufacturing, selling price and the warranty period for the final remanufactured products to investigate the joint optimization of remanufacturing, pricing and warranty decision-making for end-of-life products [23].

\section{Advanced Remanufacturing-To-Order Sys- tem Description}

The Advanced Remanufacturing-To-Order (ARTO) system deliberated in this study is a product recovery system. A sensor embedded Refrigerator is considered here as an example product. Based on the condition of EOL AC, it goes through a series of recovery operations like the one shown in Figure 1. Refurbishing and Repairing processes may require reusable components to meet the demand of the product. This requirement satisfies the internal and the external component demand. Both are satisfied using disassembly of recovered components.

EOL Refrigerators arrive at the ARTO system for information retrieval using radio frequency data reader which is stored in the facility's database. Then the Refrigerators 


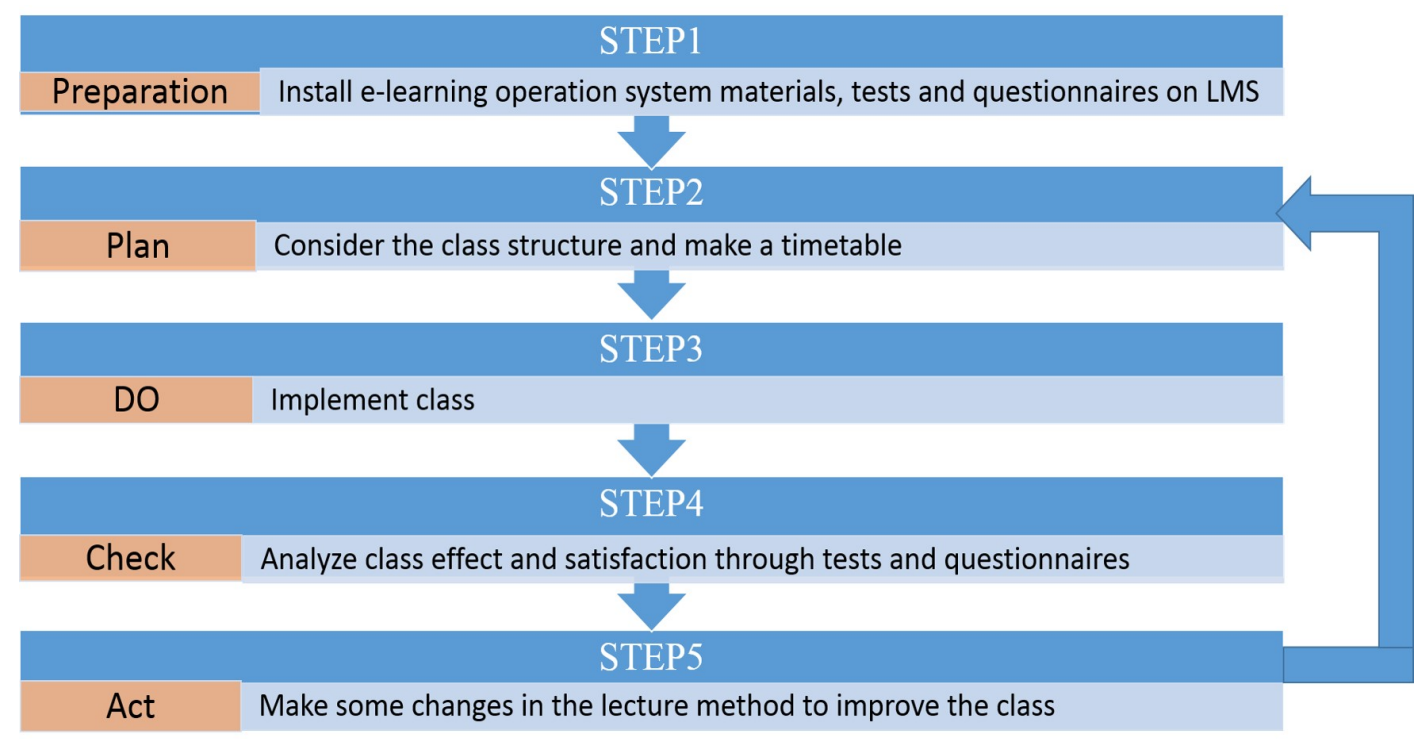

Fig. 1 ARTO System's recovery processes

Table 1 Refrigerator Components and precedence relationship

\begin{tabular}{|l|l|l|l|}
\hline Component Name & Station & Code & $\begin{array}{l}\text { Preceding } \\
\text { Component }\end{array}$ \\
\hline Metal Cover & 1 & $\mathrm{~A}$ & - \\
\hline Motor & 2 & $\mathrm{~B}$ & $\mathrm{~A}$ \\
\hline Solenoid Valve & 3 & $\mathrm{C}$ & $\mathrm{A}, \mathrm{B}$ \\
\hline Condenser & 3 & $\mathrm{D}$ & $\mathrm{A}, \mathrm{B}, \mathrm{C}$ \\
\hline Fan & 4 & $\mathrm{E}$ & $\mathrm{A}, \mathrm{B}, \mathrm{C}, \mathrm{D}$ \\
\hline $\begin{array}{l}\text { Aluminium Radia- } \\
\text { tor }\end{array}$ & 5 & $\mathrm{~F}$ & $\mathrm{~A}, \mathrm{~B}, \mathrm{C}, \mathrm{D}, \mathrm{E}$ \\
\hline Evaporator & 5 & $\mathrm{G}$ & $\mathrm{F}$ \\
\hline Compressor Con- & 6 & $\mathrm{H}$ & $\mathrm{F}, \mathrm{G}$ \\
\hline $\begin{array}{l}\text { Temperature } \\
\text { trol }\end{array}$ & 6 & $\mathrm{H}$ \\
\hline
\end{tabular}

go through a six-station disassembly line. Complete disassembly is performed to extract every single component. Table 1 represents the precedence of relationships between the refrigerator components. There are nine components in a Refrigerator consisting of, evaporator, Metal Cover, Solenoid Valve, Temperature Controls, Evaporator, motor, condenser, fan, Aluminum Radiator, and compressor. Exponential distributions are used to generate the disassembly times at each station, interarrival times of each component's demand, and interarrival times of EOL AC. All EOLPs after retrieval of the information are shipped either to station 1 for disassembly or, if EOLP needs only repair for specific component, to the corresponding station. Two different types of disassembly operations, viz., destructive or nondestructive, are used depending on the component's condition. If the disassembled component is nonfunctional (broken, zero remaining life), then destructive disassembly is used making sure that the other components' functionality is not damaged. The unit disassembly cost for a functional component is higher than nonfunctional component. After disassembly, there is no need for component testing due to the availability of information on components' conditions from sensors. It is assumed that the demands and life cycle information for EOLPs are known. It is also assumed that retrieval of information from sensors costs less than actual inspection and testing.

Recovery operations differ for each SEP based on its condition and estimated remaining life. Recovered components are used to meet components and spare parts demands, while recovered or refurbished products are used for product demands. Also, material demands are met using recycled products and components. Recovered products, and components are characterized based on their remaining life times and are placed in different life-bins (e.g. 1 year, 2 years, etc.) waiting to be retrieved via a customer demand. Underutilization of any product or component could happen when it is qualified for a higher life-bin and is placed in a lower life bin because the higher life bin is full. Any product, component or material inventory which is greater than the maximum inventory allowed is assumed to be extra and is used for material demand or disposed. To meet the product demand, repair and refurbish options could also be chosen. EOLP may have missing or nonfunctional (broken, zero remaining life) components that need to be replaced or replenished during the repairing or refurbishing process to meet certain remaining life requirement. EOLP may also consist of components having lesser remaining lives than desired, and for that reason might have to be replaced.

\section{Design-Of-Experiments Study}

According to a comprehensive study for the quantitative evaluation of the SEPs on the performance of a disassembly line conducted by Ilgin and Gupta,[20], it was show that smart SEPs are a favorable resolution in handling remanufacturing customer uncertainty. To test this claim on ARTO, we built a simulation model to represent the full recovery system and observed its behavior under different 
Table 2 Parameters used in the ARTO system

\begin{tabular}{|c|c|c|c|c|c|}
\hline Parameters & Unit & Value & Parameters & Unit & Value \\
\hline Backorder cost rate & $\%$ & 40 & Price for 3 Years Evaporator & $\$$ & 15 \\
\hline Holding cost rate & $\$ /$ hour & 10 & Price for 3 Years Motor & $\$$ & 60 \\
\hline Remanufacturing cost & $\$$ & 1.5 & Price for 3 Years Condenser & $\$$ & 25 \\
\hline Disassembly cost per minute & $\$$ & 1 & Price for 3 Years Fan & $\$$ & 20 \\
\hline Price for 1 Year Metal Cover & $\$$ & 10 & Price for 3 Years Aluminium Radiator & $\$$ & 20 \\
\hline Price for 1 Year Solenoid Valve & $\$$ & 20 & Price for 3 Years Compressor & $\$$ & 65 \\
\hline Price for 1 Year Temperature Controls & $\$$ & 5 & Weight for Metal Cover & lbs. & 8 \\
\hline Price for 1 Year Evaporator & $\$$ & 5 & Weight for Solenoid Valve & lbs. & 4 \\
\hline Price for 1 Year Motor & $\$$ & 45 & Weight for Temperature Controls & lbs. & 2 \\
\hline Price for 1 Year Condenser & $\$$ & 15 & Weight for Evaporator & lbs. & 2 \\
\hline Price for 1 Year Fan & $\$$ & 15 & Weight for Motor & lbs. & 6 \\
\hline Price for 1 Year Aluminium Radiator & $\$$ & 15 & Weight for Condenser & lbs. & 12 \\
\hline Price for 1 Year Compressor & $\$$ & 50 & Weight for Fan & lbs. & 3 \\
\hline Price for 2 Years Metal Cover & $\$$ & 15 & Weight for Aluminium Radiator & lbs. & 3 \\
\hline Price for 2 Years Solenoid Valve & $\$$ & 30 & Weight for Compressor & lbs. & 6 \\
\hline Price for 2 Years Temperature Controls & $\$$ & 12 & Unit copper scrap revenue & $\$ / \mathrm{lbs}$ & 0.6 \\
\hline Price for 2 Years Evaporator & $\$$ & 12 & Unit Fiberglass scrap revenue & $\$ / \mathrm{lbs}$ & 0.9 \\
\hline Price for 2 Years Motor & $\$$ & 55 & Unit steel scrap revenue & $\$ / \mathrm{lbs}$ & 0.2 \\
\hline Price for 2 Years Condenser & $\$$ & 18 & Unit disposal cost & $\$ / \mathrm{lbs}$ & 0.3 \\
\hline Price for 2 Years Fan & $\$$ & 18 & Unit copper scrap Cost & $\$ / \mathrm{lbs}$ & 0.3 \\
\hline Price for 2 Years Aluminium Radiator & $\$$ & 20 & Unit Fiberglass Scrap Cost & $\$ / \mathrm{lbs}$ & 0.45 \\
\hline Price for 2 Years Compressor & $\$$ & 60 & Unit steel scrap Cost & $\$ / \mathrm{lbs}$ & 0.1 \\
\hline Price for 3 Years Metal Cover & $\$$ & 20 & Price of 1 Year AC & $\$$ & 180 \\
\hline Price for 3 Years Solenoid Valve & $\$$ & 35 & Price of 2 Years $\mathrm{AC}$ & $\$$ & 240 \\
\hline Price for 3 Years Temperature Controls & $\$$ & 15 & Price of 3 Years $\mathrm{AC}$ & $\$$ & 275 \\
\hline Operation costs for Metal Cover & $\$$ & 4 & Operation costs for Condenser & $\$$ & 1.66 \\
\hline Operation costs for Solenoid Valve & $\$$ & 4 & Operation costs for Fan & $\$$ & 2.34 \\
\hline Operation costs for Temperature Controls & $\$$ & 2.8 & Operation costs for Aluminium Radiator & $\$$ & 0.6 \\
\hline Operation costs for Evaporator & $\$$ & 1.2 & Operation costs for Compressor & $\$$ & 3.4 \\
\hline Operation costs for Motor & $\$$ & 4 & Operation costs for $\mathrm{AC}$ & $\$$ & 55 \\
\hline
\end{tabular}

experimental conditions. ARENA program, Version 14.5, was used to build the discrete-event simulation models. A three-level factorial design was used with 51 factors that were considered each at 3 levels. These were identified as low, intermediate, or high levels. The reason that the three-level designs were proposed was to model possible curvature in the response function and to handle the case of nominal factors occurring at 3 levels. The parameters, factors, and factor levels are given in Table 2 and Table 3. A full-factorial design with 54 factors at 3 levels requires an extensive number of experiments (viz., $5.815 \mathrm{E}+25$ ). To reduce the number of experiments to a practical level, a small set of all the possible combinations was picked. The selection method of an experiment's number is called a partial fraction experiment, which yields the most information possible of all the factors that affect the performance parameter with minimum number of experiments possible. For these types of experiments, Taguchi (1986), enacted specific guidelines. A new method of conducting the experimental design was to use a special set of arrays called orthogonal arrays (OAs) that were built by Taguchi. Orthogonal arrays provided a way to only conduct a minimal number of experiments. In most cases, orthogonal array is more efficient when compared to many other statistical designs. The minimum number of experiments that are required to conduct the Taguchi method can be calculated based on the degrees of freedom approach.

So, the number of experiments must be greater than or equal to a system's degrees-of-freedom. The Precisely,
L109(354) (i.e., 109= [(Number of levels -1) x Number of Factors] +1) Orthogonal Arrays were chosen because the degree of freedom ARTO system is 101, meaning it requires 101 experiments to accommodate 54 factors upon three different levels. Additionally, orthogonal array assumes that there is no interaction between any two factors.

Furthermore, for validation and verification purposes animations of the simulation models were built along with multiple dynamic and counters plots. 2,000 replications with six months (eight hours a shift, one shifts a day and 5 days a week) were used to run each experiment. Arena models calculate the profit using the following equation:

$$
\begin{aligned}
& \text { Profit }=S R+C R+S C R-H C-B C-D C-D P C- \\
& T C-R M C-T P C-W C
\end{aligned}
$$

where SR is the total revenue generated by the product; component and material sales during the simulated run time; CR is the total revenue generated by the collection of EOL refrigerators during the simulated run time; SCR is the total revenue generated by selling scrap components during the simulated run time; $\mathrm{HC}$ is the total holding cost of products, components, material and EOL refrigerators during the simulated run time; BC is the total backorder cost of products, components and material during the simulated run time; DC is the total disassembly cost during the simulated run time; DPC is the total disposal cost of components, material and EOL refrigerators during the 
Table 3 Factors and factor levels used in design-of-experiments study

\begin{tabular}{|c|c|c|c|c|c|}
\hline \multirow{2}{*}{ No } & \multirow{2}{*}{ Factor } & \multirow{2}{*}{ Unit } & \multicolumn{3}{|c|}{ Levels } \\
\hline & & & 1 & 2 & 3 \\
\hline 1 & Mean arrival rate of EOL Refrigerators & Products/hour & 10 & 20 & 30 \\
\hline 2 & Probability of Repair EOLPs & $\%$ & 5 & 10 & 15 \\
\hline 3 & Probability of a non-functional Solenoid Valve & $\%$ & 10 & 20 & 30 \\
\hline 4 & Probability of a non-functional motor & $\%$ & 10 & 20 & 30 \\
\hline 5 & Probability of a non-functional fan & $\%$ & 10 & 20 & 30 \\
\hline 6 & Probability of a non-functional compressor & $\%$ & 10 & 20 & 30 \\
\hline 7 & Probability of a missing Solenoid Valve & $\%$ & 5 & 10 & 15 \\
\hline 8 & Probability of a missing motor & $\%$ & 5 & 10 & 15 \\
\hline 9 & Probability of a missing fan & $\%$ & 5 & 10 & 15 \\
\hline 10 & Probability of a missing compressor & $\%$ & 5 & 10 & 15 \\
\hline 11 & Mean non-destructive disassembly time for station 1 & Minutes & 1 & 1 & 1 \\
\hline 12 & Mean non-destructive disassembly time for station 2 & Minutes & 1 & 1 & 1 \\
\hline 13 & Mean non-destructive disassembly time for station 3 & Minutes & 1 & 1 & 1 \\
\hline 14 & Mean non-destructive disassembly time for station 4 & Minutes & 1 & 1 & 1 \\
\hline 15 & Mean non-destructive disassembly time for station 5 & Minutes & 1 & 1 & 1 \\
\hline 16 & Mean non-destructive disassembly time for station 6 & Minutes & 1 & 2 & 2 \\
\hline 17 & Mean destructive disassembly time for station 1 & Minutes & 0 & 1 & 1 \\
\hline 18 & Mean destructive disassembly time for station 2 & Minutes & 0 & 1 & 1 \\
\hline 19 & Mean destructive disassembly time for station 3 & Minutes & 0 & 1 & 1 \\
\hline 20 & Mean destructive disassembly time for station 4 & Minutes & 0 & 1 & 1 \\
\hline 21 & Mean destructive disassembly time for station 5 & Minutes & 0 & 1 & 1 \\
\hline 22 & Mean destructive disassembly time for station 6 & Minutes & 1 & 1 & 1 \\
\hline 23 & Mean Assembly time for station 1 & Minutes & 1 & 1 & 2 \\
\hline 24 & Mean Assembly time for station 2 & Minutes & 1 & 1 & 2 \\
\hline 25 & Mean Assembly time for station 3 & Minutes & 1 & 1 & 2 \\
\hline 26 & Mean Assembly time for station 4 & Minutes & 1 & 1 & 1 \\
\hline 27 & Mean Assembly time for station 5 & Minutes & 1 & 1 & 2 \\
\hline 28 & Mean Assembly time for station 6 & Minutes & 1 & 2 & 2 \\
\hline 29 & Mean demand rate Metal Cover & Parts/hour & 10 & 15 & 20 \\
\hline 30 & Mean demand rate for Solenoid Valve & Parts/hour & 10 & 15 & 20 \\
\hline 31 & Mean demand rate for Temperature Controls & Parts/hour & 10 & 15 & 20 \\
\hline 32 & Mean demand rate for Evaporator & Parts/hour & 10 & 15 & 20 \\
\hline 33 & Mean demand rate for Motor & Parts/hour & 10 & 15 & 20 \\
\hline 34 & Mean demand rate for Condenser & Parts/hour & 10 & 15 & 20 \\
\hline 35 & Mean demand rate for Fan & Parts/hour & 10 & 15 & 20 \\
\hline 36 & Mean demand rate for Aluminium Radiator & Parts/hour & 10 & 15 & 20 \\
\hline 37 & Mean demand rate for Compressor & Parts/hour & 10 & 12 & 20 \\
\hline 38 & Mean demand rate for 1 Year $\mathrm{AC}$ & Products/hour & 5 & 10 & 15 \\
\hline 39 & Mean demand rate for 2 Years AC & Products/hour & 5 & 10 & 15 \\
\hline 40 & Mean demand rate for 3 Years AC & Products/hour & 5 & 10 & 15 \\
\hline 41 & Mean demand rate for Refurbished AC & Products/hour & 5 & 10 & 15 \\
\hline 42 & Mean demand rate for Material & Products/hour & 5 & 10 & 15 \\
\hline 43 & Percentage of Good Parts to Recycling & $\%$ & 95 & 90 & 80 \\
\hline 44 & Mean Metals Separation Process & Hour & 1 & 1 & 2 \\
\hline 45 & Mean Copper Recycle Process & Minutes & 1 & 1 & 2 \\
\hline 46 & Mean Steel Recycle Process & Minutes & 1 & 1 & 2 \\
\hline 47 & Mean Fiberglass Recycle Process & Minutes & 1 & 1 & 2 \\
\hline 48 & Mean Dispose Process & Minutes & 1 & 1 & 1 \\
\hline 49 & Maximum inventory level for $\mathrm{AC}$ & Products/hour & 10 & 15 & 20 \\
\hline 50 & Maximum inventory level for Refurbished Refrigerator & Products/hour & 10 & 15 & 20 \\
\hline 51 & Maximum inventory level for Refrigerator Component & Products/hour & 10 & 15 & 20 \\
\hline 52 & Level of Preventive Maintenance effort & - & 0.5 & 0.6 & 0.7 \\
\hline 53 & Number of Preventive Maintenance to perform & \# & 2 & 3 & 4 \\
\hline 54 & Time between each Preventive Maintenance & Months & 1 & 2 & 3 \\
\hline
\end{tabular}

simulated run time. TC is the total testing cost during the simulated run time; $\mathrm{RMC}$ is the total remanufacturing cost of products during the simulated run time; TPC is the total transportation cost during the simulated run time; WC is the total warranty cost.

\section{One-Dimensional Product Warranty}

To purchase any product, typically a buyer compares features of a product with other competing manufacturers. In many cases the competing manufacturers make similar products with comparable features such as cost, special characteristics, quality and credibility of the product and 
even insurance from provider. In these cases, after sale factors such as discount, warranty, availability of parts, repairs and other additional services play a role. In such a situation, these factors will be very noteworthy to the buyer, especially the warranty since it further assures the buyer of the reliability of the product [10].

The objective of the warranty is to promote the product's quality and guarantee its performance to assure both the remanufacturer and the buyer. There are many different available simple and combination warranty polices. The combination warranty results when warranty terms change at one or more points in time during the warranty interval, $[0, \mathrm{~W}]$. Warranty coverage in each subinterval may follow a different warranty policy. The most common combination in nearly all types of applications is an initial period of Free Replacement warranty (FRW) coverage, followed by a usually longer period under Pro-Rata warranty (PRW). In a combination FRW/PRW policy, the remanufacturer agrees to provide the consumer with a replacement or repair free of charge up to time W1 from the initial purchase, $[0, \mathrm{~W} 1)$. Any failure that occurs during the $[\mathrm{W} 1, \mathrm{~W})$ period results in pro-rated refund.

\section{Notation and Formulation}

The nomenclature used in this paper is given in Table 4 .

The expected number of failures in $\left[0, W_{1}\right)$ is given by:

$$
\begin{aligned}
& E\left[N_{i}\left(W_{1} ; A\right)\right]=\left[F_{i 1}\left(W_{1}\right)\right. \\
& +\int_{0}^{W_{1}} M_{i u}\left(W_{1}-x\right) d F_{i 1}(x)
\end{aligned}
$$

Therefore, the expected warranty cost to the remanufacturer for failures in $\left[0, W_{1}\right)$ is given by:

$$
\begin{aligned}
& E\left[C_{d}\left(W_{1} ; A\right)\right]=C_{r}\left[F_{i 1}\left(W_{1}\right)\right. \\
& +\int_{0}^{W_{1}} M_{i u}\left(W_{1}-x\right) d F_{i 1}(x)
\end{aligned}
$$

For failures over the interval $[\mathrm{W} 1, \mathrm{~W})$. It needs the excess age, Y, when the warranty term changes from FRW to $\mathrm{PRW}$ is given by:

$$
\begin{aligned}
& F_{W}(y)=F_{i} 1\left(y+W_{1}\right) \\
& -\int_{0}^{W_{1}}\left[1-F_{i 1}\left(y+W_{1}-z\right)\right] d M_{i u}(z)
\end{aligned}
$$

Let the linear refund function given by:

$$
S(Y)= \begin{cases}C_{s}(A)\left\{1-\frac{W_{1}+y}{w}\right\}, & \text { if } \left.0 \leq y \leq W-W_{1}\right) \\ 0 & \text { if } Y>\left(W-W_{1}\right)\end{cases}
$$

\begin{tabular}{|c|c|}
\hline Parameters & Definition \\
\hline$L$ & Life cycle (remaining life) \\
\hline$A$ & Age at failure \\
\hline$W$ & Warranty period \\
\hline$W_{1}$ & Sun-interval of warranty period \\
\hline$Y$ & $\begin{array}{l}\text { Excess age of renewal process associ- } \\
\text { ated with failures in the period }\left[0, W_{1}\right)\end{array}$ \\
\hline$F_{w}(Y)$ & $\begin{array}{l}\text { Time when the warranty term changes } \\
\text { from FRW to PRW }\end{array}$ \\
\hline$F_{i 1}()$. & $\begin{array}{l}\text { Distribution function for times to first } \\
\text { failure }\end{array}$ \\
\hline$S(Y)$ & Linear refund function \\
\hline$M i u()$. & Renewal function \\
\hline$F_{w}()$. & $\begin{array}{l}\text { Distribution function for the first fail- } \\
\text { ure in the period }\left[W_{1}, W\right]\end{array}$ \\
\hline$F_{i 1}(x)$ & First failure function \\
\hline$C_{b}(W 1 ; A)$ & $\begin{array}{l}\text { Warranty cost to the remanufacturer } \\
\text { in the period }\left[0, W_{1}\right) \text { for an item with } \\
\text { sensor embedded }\end{array}$ \\
\hline $\begin{array}{l}C_{b}(W \\
W 1 ; Y)\end{array}$ & $\begin{array}{l}\text { Cost to the buyer in the period }\left[W_{1},\right. \\
W) \text { for an item of excess age } \mathrm{Y}\end{array}$ \\
\hline $\begin{array}{l}C_{d}(W \\
W 1 ; Y)\end{array}$ & $\begin{array}{l}\text { Warranty cost to the remanufacturer } \\
\text { in the period }\left[W_{1}, W\right) \text { for an item of } \\
\text { excess age } \mathrm{Y}\end{array}$ \\
\hline$C_{b}(W 1 . W ; A)$ & $\begin{array}{l}\text { Cost to the buyer for an item of age A } \\
\text { with sensor embedded }\end{array}$ \\
\hline$C_{d}(W 1, W ; A)$ & $\begin{array}{l}\text { Total warranty cost to the remanufac- } \\
\text { turer for item of age } A \text { with sensor em- } \\
\text { bedded }\end{array}$ \\
\hline$C_{o}$ & Operational cost per item \\
\hline$C_{r}$ & Repair cost per item \\
\hline$C_{s}$ & Sale price per item \\
\hline$C_{i}$ & $\begin{array}{l}\text { Total warranty cost for the } i \text { th inde- } \\
\text { pendent simulation run }\end{array}$ \\
\hline$S$ & Standard Error \\
\hline$K$ & $\begin{array}{l}\text { Number of independent simulation } \\
\text { run }\end{array}$ \\
\hline$\alpha$ & Confidence interval significance level \\
\hline
\end{tabular}

Then the expected warranty cost to remanufacturer resulting from a failure in $[\mathrm{W} 1, \mathrm{~W})$ is given by:

$$
\begin{aligned}
& \left.E\left[C_{d}\left(W-W_{1}\right) ; Y\right)\right]=c_{s}(A)\left[\left\{\frac{W-W_{1}}{W}\right\} F_{W}\left(W-W_{1}\right)\right. \\
& -\left(\frac{1}{W}\right) \int_{0}^{W-W_{1}} y d F_{w}(y)
\end{aligned}
$$

Table 4 List of notations

Combining the costs over the two intervals, we have

$E\left[C_{d}\left(W_{1}, W ; A\right)\right]=C_{b}\left[F_{i 1}\left(W_{1}\right)+\int_{0}^{W_{1}} M_{i u}\left(W_{1}-x\right) d F_{i 1}(x)\right]$

$+C_{s}(A)\left[\left\{\frac{W-W_{1}}{W}\right\} F_{W}\left(W-W_{1}\right)-\left(\frac{1}{w}\right) \int_{0}^{\left(W-W_{1}\right)} y d F_{W}(y)\right.$

\section{Numerical Example}

The example here considers a non-renewing onedimensional FRW/PRW policy for the remanufactured Refrigerator product with three different remaining lives (1 year, 2 years and 3 years) with three different warranty periods (1 month, 2 months and 3 months). Under this warranty, all failed items are repaired or replaced at no cost to the buyer if the failure occurs within the warranty period $[0, \mathrm{~W} 1)$. Then, any failed item in the interval $[\mathrm{W} 1$, $\mathrm{W})$ will result in a refund on a pro-rata basis. The warranty expires when the age limit is reached. The other data used for implementation of the model is shown in Table 5 . 
Table 5 Operation costs (disassembly, assembly), sale price and repair cost for Refrigerator components

\begin{tabular}{|c|c|c|c|c|c|}
\hline \multirow{2}{*}{ Components } & \multirow{2}{*}{$C_{o}=$ Operation costs $(\$ /$ unit $)$} & \multicolumn{3}{|c|}{$C_{s}=$ Sale Price $(\$ /$ unit $)$} & \multirow[t]{2}{*}{$C_{r}=$ Repair costs $(\$ /$ unit $)$} \\
\hline & & $L=1$ Year & $L=2$ Years & $L=3$ Years & \\
\hline Metal Cover & $\$ 4.00$ & $\$ 10$ & $\$ 15$ & $\$ 35$ & $\$ 8.00$ \\
\hline Control Panel & $\$ 4.00$ & $\$ 20$ & $\$ 30$ & $\$ 15$ & $\$ 8.00$ \\
\hline Agitator & $\$ 2.80$ & $\$ 5$ & $\$ 12$ & $\$ 15$ & $\$ 5.60$ \\
\hline Spin Tub & $\$ 1.20$ & $\$ 5$ & $\$ 12$ & $\$ 60$ & $\$ 2.40$ \\
\hline Motor & $\$ 4.00$ & $\$ 45$ & $\$ 55$ & $\$ 25$ & $\$ 8.00$ \\
\hline Pump & $\$ 1.66$ & $\$ 15$ & $\$ 18$ & $\$ 20$ & $\$ 3.32$ \\
\hline Water \& Drain Hoses & $\$ 2.34$ & $\$ 15$ & $\$ 18$ & $\$ 20$ & $\$ 4.68$ \\
\hline Pulley & $\$ 0.60$ & $\$ 15$ & $\$ 20$ & $\$ 65$ & $\$ 1.20$ \\
\hline Transmission & $\$ 3.40$ & $\$ 50$ & $\$ 60$ & $\$ 35$ & $\$ 6.80$ \\
\hline Refrigerator & $\$ 55.00$ & $\$ 180$ & $\$ 240$ & $\$ 310$ & $\$ 85.00$ \\
\hline
\end{tabular}

Table 6 The expected remanufacturer's warranty cost of FRW/PRW policy

\begin{tabular}{|c|c|c|c|c|c|c|c|}
\hline \multirow[t]{2}{*}{ Components } & \multirow[t]{2}{*}{$\mathrm{W}$} & \multicolumn{3}{|c|}{$\begin{array}{c}\text { Expected Number of Failures } \\
\text { During Warranty }\end{array}$} & \multicolumn{3}{|c|}{$\begin{array}{l}\text { Expected Cost to } \\
\text { Remanufacturer }\end{array}$} \\
\hline & & $\mathrm{RL}=1$ & $\mathrm{RL}=2$ & $\mathrm{RL}=3$ & $\mathrm{RL}=1$ & $\mathrm{RL}=2$ & $\mathrm{RL}=3$ \\
\hline \multirow[t]{3}{*}{ Metal Cover } & 0.5 & 0.6590 & 0.0042 & 0.0010 & $\$ 12.69$ & $\$ 14.55$ & $\$ 11.61$ \\
\hline & 1 & 0.1321 & 0.0171 & 0.0079 & $\$ 14.09$ & $\$ 15.91$ & $\$ 11.83$ \\
\hline & 2 & 0.1977 & 0.0382 & 0.0266 & $\$ 21.14$ & $\$ 20.99$ & $\$ 12.20$ \\
\hline \multirow[t]{3}{*}{ Solenoid Valve } & 0.5 & 0.6511 & 0.0041 & 0.0052 & $\$ 12.44$ & $\$ 14.46$ & $\$ 11.58$ \\
\hline & 1 & 0.1400 & 0.0168 & 0.0422 & $\$ 14.67$ & $\$ 15.51$ & $\$ 11.73$ \\
\hline & 2 & 0.1898 & 0.0380 & 0.1422 & $\$ 20.86$ & $\$ 20.59$ & $\$ 12.10$ \\
\hline \multirow[t]{3}{*}{ Temperature Controls } & 0.5 & 0.6431 & 0.0039 & 0.0274 & $\$ 6.22$ & $\$ 5.82$ & $\$ 5.94$ \\
\hline & 1 & 0.1243 & 0.0172 & 0.2260 & $\$ 8.20$ & $\$ 10.34$ & $\$ 6.10$ \\
\hline & 2 & 0.1820 & 0.0386 & 0.7599 & $\$ 11.33$ & $\$ 12.72$ & $\$ 6.32$ \\
\hline \multirow[t]{3}{*}{ Evaporator } & 0.5 & 0.6431 & 0.0018 & 0.1464 & $\$ 3.44$ & $\$ 3.34$ & $\$ 2.88$ \\
\hline & 1 & 0.0926 & 0.0175 & 1.2076 & $\$ 4.95$ & $\$ 4.55$ & $\$ 3.16$ \\
\hline & 2 & 0.1661 & 0.0334 & 0.4948 & $\$ 6.56$ & $\$ 6.50$ & $\$ 3.34$ \\
\hline \multirow[t]{3}{*}{ Motor } & 0.5 & 0.6243 & 0.0041 & 0.7825 & $\$ 13.00$ & $\$ 12.44$ & $\$ 12.17$ \\
\hline & 1 & 0.1353 & 0.0168 & 1.0149 & $\$ 14.27$ & $\$ 13.31$ & $\$ 12.38$ \\
\hline & 2 & 0.1907 & 0.0386 & 0.0212 & $\$ 20.06$ & $\$ 17.24$ & $\$ 12.51$ \\
\hline \multirow[t]{3}{*}{ Condenser } & 0.5 & 0.6503 & 0.0043 & 0.9727 & $\$ 4.06$ & $\$ 3.47$ & $\$ 3.37$ \\
\hline & 1 & 0.1266 & 0.0171 & 1.0235 & $\$ 5.88$ & $\$ 4.95$ & $\$ 3.71$ \\
\hline & 2 & 0.1993 & 0.0386 & 0.1130 & $\$ 6.81$ & $\$ 5.73$ & $\$ 3.90$ \\
\hline \multirow[t]{3}{*}{ Fan } & 0.5 & 0.6661 & 0.0039 & 1.0149 & $\$ 7.77$ & $\$ 6.56$ & $\$ 6.32$ \\
\hline & 1 & 0.1456 & 0.0170 & 0.2064 & $\$ 10.74$ & $\$ 7.68$ & $\$ 6.47$ \\
\hline & 2 & 0.1915 & 0.0383 & 0.6043 & $\$ 13.34$ & $\$ 10.68$ & $\$ 6.81$ \\
\hline \multirow[t]{3}{*}{ Aluminium Radiator } & 0.5 & 0.6725 & 0.0042 & 0.7231 & $\$ 2.04$ & $\$ 1.61$ & $\$ 1.15$ \\
\hline & 1 & 0.1243 & 0.0170 & 1.1032 & $\$ 3.19$ & $\$ 2.60$ & $\$ 1.39$ \\
\hline & 2 & 0.1890 & 0.0386 & 1.0191 & $\$ 5.57$ & $\$ 3.75$ & $\$ 1.49$ \\
\hline \multirow[t]{3}{*}{ Compressor } & 0.5 & 0.6495 & 0.0042 & 0.0216 & $\$ 9.01$ & $\$ 8.45$ & $\$ 8.08$ \\
\hline & 1 & 0.1313 & 0.0171 & 0.1130 & $\$ 11.61$ & $\$ 10.90$ & $\$ 8.76$ \\
\hline & 2 & 0.1907 & 0.0384 & 1.0235 & $\$ 15.82$ & $\$ 14.27$ & $\$ 9.04$ \\
\hline \multirow[t]{3}{*}{ Refrigerator } & 0.5 & 0.4890 & 0.0031 & 0.0003 & $\$ 78.66$ & $\$ 75.44$ & $\$ 74.73$ \\
\hline & 1 & 0.0980 & 0.0128 & 0.0019 & $\$ 82.07$ & $\$ 82.96$ & $\$ 78.23$ \\
\hline & 2 & 0.1468 & 0.0284 & 0.0065 & $\$ 96.43$ & $\$ 95.00$ & $\$ 81.14$ \\
\hline
\end{tabular}

\section{Results}

The total expected warranty costs to the remanufacturer under the above assumptions are given in Table 6 . The ARENA 14.7 program was used to compute the expected number of failures and expected cost to remanufacturer values by carrying out 2,000 independent simulation run. As can be seen that the expected warranty cost increases with the age of the item at sales, as to be expected. For instance, from Table 6 a 1 year remaining life refrigerator with a 0.5 -year warranty has cost of the warranty $\$ 78.66$, which is $23.13 \%$ of sales price, Cs $=\$ 340$. Therefore, if the total cost of the 1 year refrigerator to the remanufacturer is $\$ 156$ and it sells for $\$ 340$, the cost to the remanufacturer, including warranty, is $\$ 156.00+\$ 78.66$ $=\$ 234.66$. The confidence interval for the mean of $\mathrm{K}$ independent simulation runs with $\mathrm{K}=2,000$ is shown in Table 7 . The confidence interval is given by:

$$
\begin{aligned}
& \bar{C}(K) \mp t_{k-1}\left(1-\frac{\alpha}{2}\right) \sqrt{\frac{s^{2}(k)}{k}} \\
& \frac{s^{2}(k)}{k}=\sum \frac{\left[c_{i}-\bar{C}(k)\right]^{2}}{k-1}
\end{aligned}
$$

For 1-year remaining life sold with 0.5-year warranty we can claim with $90 \%$ confidence that the expected warranty cost is in the interval [ $\$ 74.40-\$ 78.03]$. The confidence interval for a 3 -years remaining life sold with 2-years warranty is $[\$ 66.84-\$ 90.45]$. 
Table 7 Standard Error and Confidence Interval on FRW/PRW policy

\begin{tabular}{|c|c|c|c|c|c|c|c|c|c|c|}
\hline \multirow{3}{*}{ Components } & \multirow{3}{*}{ W } & \multirow{2}{*}{\multicolumn{3}{|c|}{$\begin{array}{c}\text { Standard Error } \\
(\mathrm{S})\end{array}$}} & \multicolumn{6}{|c|}{ 90\% Confidence Interval } \\
\hline & & & & & \multicolumn{2}{|c|}{$\mathrm{RL}=1$} & \multicolumn{2}{|c|}{$\mathrm{RL}=2$} & \multicolumn{2}{|c|}{$\mathrm{RL}=3$} \\
\hline & & $\mathrm{RL}=1$ & $\mathrm{RL}=2$ & $\mathrm{RL}=3$ & L limit & U limit & L limit & U limit & L limit & U limit \\
\hline \multirow[t]{3}{*}{ Metal Cover } & 0.5 & 0.52 & 0.75 & 1.15 & $\$ 11.82$ & $\$ 12.75$ & $\$ 13.41$ & $\$ 14.76$ & $\$ 10.20$ & $\$ 12.30$ \\
\hline & 1 & 1.31 & 1.92 & 2.02 & $\$ 12.45$ & $\$ 14.85$ & $\$ 13.65$ & $\$ 17.19$ & $\$ 9.63$ & $\$ 13.32$ \\
\hline & 2 & 2.53 & 2.89 & 3.33 & $\$ 18.15$ & $\$ 22.80$ & $\$ 17.70$ & $\$ 22.98$ & $\$ 8.79$ & $\$ 14.85$ \\
\hline \multirow[t]{3}{*}{ Solenoid Valve } & 0.5 & 0.57 & 0.84 & 1.28 & $\$ 11.55$ & $\$ 12.60$ & $\$ 13.23$ & $\$ 14.79$ & $\$ 10.05$ & $\$ 12.39$ \\
\hline & 1 & 1.47 & 2.17 & 2.27 & $\$ 12.87$ & $\$ 15.57$ & $\$ 13.05$ & $\$ 16.98$ & $\$ 9.30$ & $\$ 13.44$ \\
\hline & 2 & 2.84 & 3.25 & 3.74 & $\$ 17.64$ & $\$ 22.83$ & $\$ 16.98$ & $\$ 22.92$ & $\$ 8.31$ & $\$ 15.15$ \\
\hline \multirow[t]{3}{*}{ Temperature Controls } & 0.5 & 0.64 & 0.95 & 1.45 & $\$ 5.43$ & $\$ 6.63$ & $\$ 4.77$ & $\$ 6.51$ & $\$ 4.44$ & $\$ 7.08$ \\
\hline & 1 & 1.65 & 2.43 & 2.55 & $\$ 6.42$ & $\$ 9.45$ & $\$ 7.80$ & $\$ 12.24$ & $\$ 3.57$ & $\$ 8.22$ \\
\hline & 2 & 3.19 & 3.65 & 4.20 & $\$ 8.07$ & $\$ 13.89$ & $\$ 9.00$ & $\$ 15.66$ & $\$ 2.28$ & $\$ 9.96$ \\
\hline \multirow[t]{3}{*}{ Evaporator } & 0.5 & 0.82 & 1.20 & 1.83 & $\$ 2.58$ & $\$ 4.08$ & $\$ 2.16$ & $\$ 4.35$ & $\$ 1.11$ & $\$ 4.47$ \\
\hline & 1 & 2.10 & 3.09 & 3.24 & $\$ 2.88$ & $\$ 6.72$ & $\$ 1.59$ & $\$ 7.23$ & $\$ 0.12$ & $\$ 6.00$ \\
\hline & 2 & 4.06 & 4.63 & 5.33 & $\$ 2.67$ & $\$ 10.05$ & $\$ 2.07$ & $\$ 10.53$ & $\$ 1.05$ & $\$ 8.13$ \\
\hline \multirow[t]{3}{*}{ Motor } & 0.5 & 0.73 & 1.08 & 1.63 & $\$ 11.91$ & $\$ 13.26$ & $\$ 11.10$ & $\$ 13.05$ & $\$ 10.29$ & $\$ 13.29$ \\
\hline & 1 & 1.86 & 2.75 & 2.88 & $\$ 12.12$ & $\$ 15.54$ & $\$ 10.41$ & $\$ 15.42$ & $\$ 9.39$ & $\$ 14.64$ \\
\hline & 2 & 3.61 & 4.12 & 4.74 & $\$ 16.14$ & $\$ 22.74$ & $\$ 12.93$ & $\$ 20.46$ & $\$ 7.80$ & $\$ 16.47$ \\
\hline \multirow[t]{3}{*}{ Condenser } & 0.5 & 0.61 & 0.89 & 1.35 & $\$ 3.39$ & $\$ 4.47$ & $\$ 2.55$ & $\$ 4.17$ & $\$ 2.04$ & $\$ 4.50$ \\
\hline & 1 & 1.54 & 2.27 & 2.38 & $\$ 4.29$ & $\$ 7.11$ & $\$ 2.73$ & $\$ 6.87$ & $\$ 1.44$ & $\$ 5.79$ \\
\hline & 2 & 2.98 & 3.40 & 3.92 & $\$ 3.87$ & $\$ 9.33$ & $\$ 2.43$ & $\$ 8.67$ & $\$ 0.21$ & $\$ 7.38$ \\
\hline \multirow[t]{3}{*}{ Fan } & 0.5 & 0.61 & 0.89 & 1.35 & $\$ 6.99$ & $\$ 8.10$ & $\$ 5.55$ & $\$ 7.17$ & $\$ 4.89$ & $\$ 7.35$ \\
\hline & 1 & 1.54 & 2.27 & 2.38 & $\$ 9.00$ & $\$ 11.82$ & $\$ 5.37$ & $\$ 9.54$ & $\$ 4.11$ & $\$ 8.46$ \\
\hline & 2 & 2.98 & 3.40 & 3.92 & $\$ 10.23$ & $\$ 15.66$ & $\$ 7.23$ & $\$ 13.47$ & $\$ 3.03$ & $\$ 10.20$ \\
\hline \multirow[t]{3}{*}{ Aluminium Radiator } & 0.5 & 0.58 & 0.85 & 1.30 & $\$ 1.47$ & $\$ 2.52$ & $\$ 0.78$ & $\$ 2.34$ & $\$ 0.06$ & $\$ 2.31$ \\
\hline & 1 & 1.49 & 2.19 & 2.30 & $\$ 1.71$ & $\$ 4.44$ & $\$ 0.51$ & $\$ 4.53$ & $\$ 0.51$ & $\$ 3.45$ \\
\hline & 2 & 2.88 & 3.29 & 3.79 & $\$ 2.76$ & $\$ 8.04$ & $\$ 0.63$ & $\$ 6.63$ & $\$ 1.62$ & $\$ 4.92$ \\
\hline \multirow[t]{3}{*}{ Compressor } & 0.5 & 0.58 & 0.85 & 1.30 & $\$ 8.19$ & $\$ 9.27$ & $\$ 7.41$ & $\$ 8.97$ & $\$ 6.63$ & $\$ 9.03$ \\
\hline & 1 & 1.49 & 2.19 & 2.30 & $\$ 9.87$ & $\$ 12.60$ & $\$ 8.55$ & $\$ 12.57$ & $\$ 6.39$ & $\$ 10.59$ \\
\hline & 2 & 2.88 & 3.29 & 3.79 & $\$ 12.69$ & $\$ 17.94$ & $\$ 10.83$ & $\$ 16.86$ & $\$ 5.31$ & $\$ 12.24$ \\
\hline \multirow[t]{3}{*}{ Refrigerator } & 0.5 & 0.76 & 1.11 & 1.70 & $\$ 74.40$ & $\$ 78.03$ & $\$ 70.44$ & $\$ 75.78$ & $\$ 68.37$ & $\$ 76.47$ \\
\hline & 1 & 1.94 & 2.85 & 2.99 & $\$ 74.88$ & $\$ 84.18$ & $\$ 75.87$ & $\$ 84.90$ & $\$ 68.67$ & $\$ 82.98$ \\
\hline & 2 & 3.75 & 4.29 & 4.93 & $\$ 84.48$ & $\$ 102.42$ & $\$ 81.81$ & $\$ 102.30$ & $\$ 66.84$ & $\$ 90.45$ \\
\hline
\end{tabular}

\section{Conclusion}

The warranty cost for remanufactured products was evaluated in this paper using the combination Free Replacement and Pro-Rata Warranty (FRW/PRW) for different warranty periods. The main objective was to introduce the idea of providing a non-renewable basic combination warranty for a remanufactured product using the sensor information about the age of every remanufactured product on hand to meet demands while minimizing the cost associated with warranty and maximizing remanufacturer's profit. A simulation model was used to optimize the system and predict the warranty period that should be assigned to every disassembled component and remanufactured product.

\section{References}

[1] Alqahtani, A. Y., \& Gupta, S. M. (2017). Warranty Cost Analysis within Sustainable Supply Chain. In U. Akkucuk (Ed.), Ethics and Sustainability in Global Supply Chain Management (pp. 1-25). Hershey, PA: IGI Global.

[2] Alqahtani, A. Y., \& Gupta, S. M. (2017b). Optimizing two-dimensional renewable warranty policies for sensor embedded remanufacturing products. Journal of Industrial Engineering and Management, 10(2), 73-89.

[3] Alqahtani, A.Y. \& Gupta, S.M. (2017c). One-Dimensional Renewable Warranty Management within Sustainable Supply Chain. Resources, 6(16).

[4] Balachander, S. (2001), Warranty signalling and reputation. Management Science, 47(9), 1282-1289.
[5] Blischke, W. R. and Murthy, C. N. P. (1994), Warranty cost analysis. Marcel Dekker, New York.

[6] Blischke, W. R. and Murthy, C. N. P. (1996), Product warranty handbook. Marcel Dekker, New York.

[7] Fang, H. C., S. K. Ong, and A. Y. C. Nee. (2014). Use of Embedded Smart Sensors in Products to Facilitate Remanufacturing. Handbook of Manufacturing Engineering and Technology, 3265-3290.

[8] Ferrer, G., Heath, S. K., \& Dew, N. (2011). An RFID application in large job shop remanufacturing operations. International Journal of Production Economics, 133(2), 612621.

[9] Gal-Or, E. (1989), Warranties as a signal of quality. Canadian Journal of Economics, 50-61.

[10] Godichaud, M., Peres, F., Gonzalez, V., Tchangani, A., Crespo, A. and Villeneuve, E. (2011), Integration of warranty as a decision variable in the process of recertification of parts resulting from end-of-life system dismantling. Proceedings of Quality and Reliability (ICQR), IEEE International Conference, 156-160.

[11] Gungor, A. and Gupta S.M. (1999), Issues in environmentally conscious manufacturing and product recovery: a survey. Computers and Industrial Engineering, 36, 811853.

[12] Gungor. A. and Gupta S.M. (2002), Disassembly line in product recovery. International Journal of Production Research, 40, 2569-2589.

[13] Gupta S.M., \& Lambert A.J.D. (eds) (2007). Environment conscious manufacturing. CRC Press, Boca Raton.

[14] Gupta, S. M. (2013). Reverse supply chains: issues and analysis. CRC Press. 
[15] Heal, G. (1977), Guarantees and risk-sharing. The Review of Economic Studies, 549-560.

[16] Ilgin, M. A. and Gupta, S. M. (2010), Comparison of economic benefits of sensor embedded products and conventional products in a multi-product disassembly line. Computers and Industrial Engineering, 59, 748-763.

[17] Ilgin, M. A. and Gupta, S. M. (2010), Environmentally conscious manufacturing and product recovery (ECMPRO): A review of the state of the art. Journal of Environmental Management, 91, 563-591.

[18] Ilgin, M. A. and Gupta, S. M. (2010), Evaluating the impact of sensor-embedded products on the performance of an air conditioner disassembly line. The International Journal of Advanced Manufacturing Technology, 53, 11991216.

[19] Ilgin, M. A. and Gupta, S. M. (2011), Performance improvement potential of sensor embedded products in environmental supply chains. Resources, Conservation and Recycling, 55, 580-592.

[20] Ilgin, M. A., Gupta, S. M. and Battaia, O. (2015). Use of MCDM techniques in environmentally conscious manufacturing and product recovery: State of the art. Journal of Manufacturing Systems,37, 746-758.

[21] Kiritsis D, Bufardi A, Xirouchakis P (2003) Research issues on product lifecycle management and information tracking using smart embedded systems. Advance Engineering Information 17(3-4):189-202.

[22] Kulkarni, A., Ralph, D. and McFarlane, D. (2007). Value of RFID in remanufacturing. International Journal of Services Operations and Informatics, 2(3), 225-252.

[23] Liao, B. F., LI, B. Y. and Cheng, J. S. (2015). A warranty model for remanufactured products. Journal of Industrial and Production Engineering, 32(8), 551-558.

[24] Lutz, N. A. and Padmanabhan, V. (1995), Why do we observe minimal warranties- Marketing Science, 14(4), 417441.

[25] Murthy, D. P. and Blischke, W. R. (2006), Warranty management and product manufacture. Springer, London.

[26] Parlikad, A. K., \& McFarlane, D. (2007). RFID-based product information in end-of-life decision making. Control engineering practice, 15(11), 1348-1363.

[27] Pecht, M. (2008). Prognostics and health management of electronics. John Wiley \& Sons, Ltd., Hoboken.

[28] Soberman, D. A. (2003), Simultaneous signaling and screening with warranties. Journal of Marketing Research, 40(2), 176-192.

[29] Spence, M. (1977), Consumer misperceptions, product failure and producer liability. The Review of Economic Studies, 561-572.

[30] Vadde, S, Kamarthi, SV, Gupta, SM, Zeid I (2008) Product life cycle monitoring via embedded sensors. In: Gupta SM, Lambert AJD, Environment conscious manufacturing. 91-103.

[31] Zeid A, Kamarthi S, and Gupta SM (2004). Product takeback: sensors-based approach. In: Gupta SM Environmentally conscious manufacturing IV. Proceedings of SPIE, Vol 5583. Bellingham, 200-206.

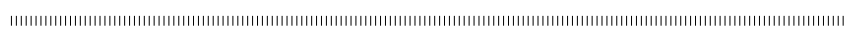

\section{Ammar Y. Alqahtani}

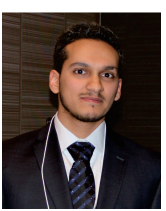

is a faculty member of department of Industrial Engineering at King Abdulaziz University in Jeddah, Saudi Arabia. He received his B.Sc. in Industrial Engineering from King Abdulaziz University, M.Sc. from University of Houston, and Ph.D. in Industrial Engineering from Northeastern University. His research interests are in the areas of environmentally conscious manufacturing, product recovery, reverse logistics, closed-loop supply chains (CLSC), sustainable operations, and sustainability, simulation and Statistical analysis and modeling with applications in CLSC and multiple lifecycle products. Alqahtani has served as session chair in NEDSI, POMS, DSI and IISE conferences. He has served as reviewer for scientific journals such as Computer and Industrial Engineering, Decision Sciences and Journal of Industrial Engineering and Management. At Northeastern University, he won the Alfred J. Ferretti for excellent in research award. He also received the 33rd Quality \& Productivity Research conference award from the American Statistical Association.

\section{Surendra M. Gupta}

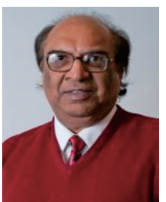

is a Professor of Mechanical and Industrial Engineering and the Director of the Laboratory for Responsible Manufacturing, Northeastern University. He received his BE in Electronics Engineering from Birla Institute of Technology and Science, MBA from Bryant University, and MSIE and Ph.D. in Industrial Engineering from Purdue University. He is a registered professional engineer in the State of Massachusetts. Dr. Gupta's research interests are in the areas of Production/Manufacturing Systems and Operations Research. He is mostly interested in Environmentally Conscious Manufacturing, Reverse and Closed-Loop Supply Chains, Disassembly Modeling and Remanufacturing. Dr. Gupta has coauthored nine books including "Reverse Supply Chains: Issues and Analysis" and "Green Supply Chain Management: Product Life Cycle Approach”, which were named as Industrial Engineer Magazine Books of the Month in 2013 and 2011 respectively. He has authored or co-authored well over 500 technical papers published in books, journals and international conference proceedings. His publications have been cited by thousands of researchers all over the world in journals, proceedings, books, and dissertations. He has traveled to all seven continents viz., Africa, Antarctica, Asia, Australia, Europe, North America and South America and presented his work at international conferences on six continents. Dr. Gupta has taught over 100 courses in such areas as operations research, inventory theory, queuing theory, engineering economy, supply chain management, and production planning and control. Among the many recognitions received, he is the recipient of outstanding research award and outstanding industrial engineering professor award (in recognition of teaching excellence) from Northeastern University as well as a national outstanding doctoral dissertation advisor award. He has been elected to memberships and chairmanships of dozens of University, College and Department Committees as well as an elected member of the Faculty Senate representing the College of Engineering. 


\section{Kenichi NaKashima}

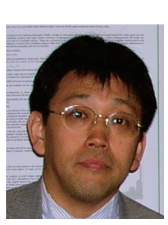

is a Professor in the Department of Industrial Engineering and Management at Kanagawa University, Japan. He received his $\mathrm{BE}, \mathrm{MS}$ and $\mathrm{PhD}$ in Industrial Engineering from Nagoya Institute of Technology, Nagoya, Japan, in 1990, 1992 and 1995, respectively. From 1995 to 1996, he was a Research Associate in the Department of Industrial Management, Osaka Institute of Technology. He was an Assistant Professor from 1996 to 2000 and an Associate Professor from 2000 to 2010 in the Department of Industrial Management, Osaka Institute of Technology. He was also a visiting Assistant Professor at MIT in 1998. Dr. Nakashima received the Research Award for young researchers from Japan Industrial Management Association in 1997. He has served as members of technical committees of international conferences. His research interests include dynamic programming, Markov decision processes, production management and management information systems. His papers have appeared in International Journal of Production Research, International Journal of Production Economics and IEEE Transactions on Systems, Man and Cybernetics (Part A). 